\title{
IMPROVING EFFICIENCY OF MILKING MACHINE VACUUM CONTROL
}

\author{
Yuriy Ushakov, Vladimir Shakhov, Nina Komarova, Ilmira Rakhimzhanova \\ Orenburg State Agrarian University, Russia \\ 1u6j1a159@mail.ru, shahov-v@yandex.ru,1u6j1a159komarova@mail.ru, ahmetova_i@mail.ru
}

\begin{abstract}
The stereotype of cows' machine milking and this process efficiency largely depend on the static and dynamic stability of the vacuum mode in the vacuum line of milking plants. Value destabilization of the underside vacuum, pulsation frequency and the stroke ratio, the nature of the effect of the nipple rubber on the nipple of the udder due to fluctuations of the main vacuum lead to a decrease in the rate of milking, a decrease in the productivity of animals, the disease of animals mastitis and other negative consequences. Analysis of the air flow dynamics by the vacuum system and the vacuum regulator makes it possible to predict the operation of the milking unit in a malfunctioning state and take timely measures to exclude such operating modes. The research range was controlled by the coefficient of dynamic stability of rarefaction at an unfavorable point (the ratio of the length of the curve of the actual change in rarefaction to the projection of this curve on the time axis). The group of simultaneously operating milking units was evaluated by the ripple frequency stability coefficient. Sensitivity of various controlled parameters (air flow rate by the system, air flow rate by the vacuum regulator, sum and difference of these flows, mathematical expectations and dispersion of these parameters) to main failures of the vacuum system is established (vacuum system depressurization, pipeline clogging, technology compliance by cow milking operators, milking apparatus performance, vacuum pump capacity, etc.). The possibility of preliminary formation of control action to exclude operation of the vacuum system with vacuum mode disorders is shown.
\end{abstract}

Keywords: milking, milking machine, vacuum, vacuum line, control, stability, malfunction.

\section{Introduction}

The dairy industry, among other agricultural sectors, is most socially important for strengthening and developing rural areas in all regions [1;2]. A smart farm is a highly automated farm [2;3]. In such a farm, thanks to the intellectual component in the design and management of machines, farmers can combine the data obtained from sensors with the knowledge of specialists [3; 4]. According to foreign experts [4-6], a "smart" farm should provide owners of modern dairy farms with a decision support tool and automation technologies that will seamlessly combine equipment, services and the intellectual component (knowledge) to improve milk quality, manage the herd, and increase productivity and profitability [1]. In a milking installation, it is important to provide static or dynamic stability of the vacuum regime [7;8]. For early warning of the operation of the vacuum system of the milking unit with deviations of the parameters from the norm, timely information is needed. Therefore, the paper discusses the dynamics of changes in the air flow rates by the vacuum system and the vacuum regulator in the operating mode of the milking unit with a stable vacuum mode.

\section{Materials and methods}

The object of study are milking machines: УДЕ-М(2x6), (equipment for twelve machines); ADM-8A-100; AD-100. We used a recording device for testing the "Tensor 7" milking machines (measurement accuracy $\pm 1.5 \%$ ). The flow rate was measured with a diaphragm-type constricting device. Diaphragm modules $\mathrm{m}$ for different flow ranges are summarized in Table 1.

Table 1

Diaphragm modules for different flow ranges (at a pressure in the pipeline of $50 \mathrm{kPa}$ and $100 \mathrm{kPa}$ )

\begin{tabular}{|c|c|c|c|c|c|c|c|}
\hline \multicolumn{2}{|c|}{$\boldsymbol{Q}^{-10^{-3}} \mathbf{~ m}^{\mathbf{3}} \cdot \mathbf{s}^{-1}$} & 5.56 & 11.11 & 16.67 & 22.22 & 27.78 & 33.33 \\
\hline \multirow{2}{*}{$m$} & $P=50, \mathrm{kPa}$ & 0.26 & 0.47 & 0.64 & 0.64 & 0.64 & 0.70 \\
\cline { 2 - 8 } & $P=100, \mathrm{kPa}$ & 0.18 & 0.35 & 0.49 & 0.61 & 0.69 & 0.70 \\
\hline
\end{tabular}

Air rate by the system $Q_{s}(t)$ is a random, stationary, ergodic process with constant mathematical expectation, dispersion, and a correlation function [7; 9]. Our studies have shown that it will be more accurate to represent it as the sum of two random processes

$$
Q_{s}(t)=\xi_{s}^{1}(t)+\xi_{s}^{2}(t)
$$


where $t$ - milking unit operating time, $\mathrm{s}$;

$\xi_{s}^{1}(t)$ - random time function with zero expectation, $\mathrm{m}^{3} \cdot \mathrm{s}^{-1}$;

$\xi_{s}^{2}(t)$ - random time function with non-zero expectation, $\mathrm{m}^{3} \cdot \mathrm{s}^{-1}$.

The first random process $\xi_{s}^{1}(t)$ has zero mathematical expectation and is due to the imposition of the pulsating costs of individual milking machines, the synchronism and asynchrony of their work. The second random process $\xi_{s}^{2}(t)$ has a non-zero mathematical expectation and is a function of the technical condition of the vacuum line, adherence to technology by operators, the number of milking machines working simultaneously.

Since the air flow by the vacuum regulator $Q_{r}(t)$ is a distorted mirror image of the dynamics of the air flow rate by the vacuum system $Q_{s}(t)$, it can also be represented by the sum of two random processes

$$
Q_{r}(t)=\xi_{r}^{1}(t)+\xi_{r}^{2}(t),
$$

where $\xi_{r}^{1}(t)$-random time function with zero expectation, $\mathrm{m}^{3} \cdot \mathrm{s}^{-1}$;

$\xi_{r}^{2}(t)$ - random time function with non-zero expectation, $\mathrm{m}^{3} \cdot \mathrm{s}^{-1}$.

A comparison of the dynamics of the air flow rates of the vacuum system $Q_{s}(t)$ with the dynamics of the air flow rates of the vacuum regulator $Q_{r}(t)$ allows us to evaluate the stability of the working vacuum in the vacuum system $[9 ; 10]$. Omitting the intermediate transformations, it is easy to show the equality

$$
Q_{s}(t)-Q_{s}(t)=\xi_{s}^{1}(t)+\xi_{s}^{2}(t)-\xi_{r}^{1}(t)-\xi_{r}^{2}(t)=\xi(t),
$$

where $\xi(t)$-some time function characterizing the stability of the vacuum regime, $\mathrm{m}^{3} \cdot \mathrm{s}^{-1}$.

Using this function as a controlled parameter increases the efficiency of monitoring the vacuum regime of milking units. The coefficient of sensitivity $k_{\xi}$ of the function $\xi(t)$ to a change in the magnitude of the vacuum in the system is greater than the sensitivity coefficients $k_{Q i}$ of individual air flow rates $Q_{i}(t)$. Sensitivity coefficients are determined by dependencies

$$
k_{Q_{i}}=\Delta P(t) / \Delta Q_{i}(t) \quad k_{\xi}=\Delta P / \Delta \xi(t),
$$

where $\Delta P(t)$ - pressure change, $\mathrm{Pa}$;

$\Delta Q_{i}(t)$ - change in corresponding air flow rates, $\mathrm{m}^{3} \cdot \mathrm{s}^{-1}$;

$\Delta \xi(t)$ - change in the difference between the air flow rates of the system and the air flow rates of the vacuum regulator, $\mathrm{m}^{3} \cdot \mathrm{s}^{-1}$.

The dynamics of the air flow by the vacuum regulator $Q_{r}(t)$ depends on the dynamics of the air flow by the vacuum system $Q_{s}(t)$. The most probable value of the mathematical expectation of the ratio of sensitivity coefficients tends to a value of 0.5 .

$$
k_{\xi} / k_{Q_{i}}=[\Delta P(t) / \Delta \xi(t)] /\left[\Delta P(t) / \Delta Q_{i}(t)\right]=\Delta Q_{i}(t) / \Delta \xi(t) .
$$

The left side of equation (3) is a composition of two paired compositions of random processes. The rules of probability theory and mathematical statistics allow us to represent the right side of equation (3) as a composition of two random processes

$$
\xi(t)=\xi_{1}(t)+\xi_{2}(t),
$$

where $\xi_{1}(t)$-random time function with zero expectation, $\mathrm{m}^{3} \cdot \mathrm{s}^{-1}$;

$\xi_{2}(t)$ - random time function with non-zero expectation, $\mathrm{m}^{3} \cdot \mathrm{s}^{-1}$.

The mathematical expectation of the second random process correlates with the actual capacity of the vacuum pump and the magnitude of the depressurization of the vacuum system [10]. The dispersion of the first random process depends on the clogging of the pipeline [11; 12]. As a rule, clogging is determined by the trend of the statistical coefficient associated with the actual coefficient of resistance of the pipeline $\lambda$. The statistical coefficient has a complex nature and hardware definition. By methods of regression analysis, a linear dependence of the trend of the statistical coefficient relative to the square root of the resistance coefficient was established $\lambda$ [7]. 
The correlation function of the first random process is proportional to the pulsation frequency of milking machines. The dispersion of the second random process depends on the observance of the technology by the operators when setting and removing milking cups (the ratio of the number of leaks to the total number of installations of milking cups). In essence, the goal of control is reduced to the task of distinguishing between two random processes $\xi_{1}(t)$ and $\xi_{2}(t)$ their characteristics.

The experimental studies consisted of twelve experiments. They varied by the number of simultaneously working milking machines; ripple frequency; the ratio between the numbers of milking machines working with different frequencies in one group. The study relied on the requirements for the parameters of milking machines [13].

The first three experiments were carried out with a pulse frequency of $1.00 \mathrm{~Hz}$ at a load of six, eight and ten milking machines, respectively. The following three experiments were carried out with a frequency of $1.33 \mathrm{~Hz}$ at a load of six, eight and ten milking machines, respectively. Three more experiments were carried out with a frequency of $1.8 \mathrm{~Hz}$ at a load of six, eight and ten milking machines, respectively. In the tenth experiment, five devices worked with a pulse frequency of $1 \mathrm{~Hz}$ and five with a frequency of $1.33 \mathrm{~Hz}$; in the eleventh, half with a frequency of $1 \mathrm{~Hz}$ and half with a frequency of $1.8 \mathrm{~Hz}$; in the twelfth, five with a frequency of $1.8 \mathrm{~Hz}$ and five with a frequency of $1.33 \mathrm{~Hz}$.

The sensitivity coefficients of mathematical expectations and dispersions of controlled parameters were determined as follows:

to change of pulsation frequency

$$
\left(Q_{i}^{\max }-Q_{i}^{\min }\right) / \Delta f,\left(D_{i}^{\max }-D_{i}^{\min }\right) / \Delta f ;
$$

to change of stability of pulsation frequency

$$
\left(Q_{i}^{\max }-Q_{i}^{\min }\right) / \Delta i,\left(D_{i}^{\max }-D_{i}^{\min }\right) / \Delta i ;
$$

to change in vacuum line load

$$
\left(Q_{i}^{\max }-Q_{i}^{\min }\right) / \Delta f,\left(D_{i}^{\max }-D_{i}^{\min }\right) / \Delta f ;
$$

where $Q_{i}^{\max }, Q_{i}^{\min }$ - maximum and minimum value of mathematical expectation corresponding controlled parameter, $\mathrm{m}^{3} \cdot \mathrm{s}^{-1}$;

$D_{i}^{\max }, D_{i}^{\min }$ - maximum and minimum dispersion values of the respective controlled parameters, $\mathrm{m}^{6} \cdot \mathrm{s}^{-2}$;

$\Delta f$ - increment of pulsation frequency of group of simultaneously operating milking devices, $\mathrm{Hz}$;

$\Delta i$-increment of the number of milking units operating simultaneously;

$k_{f}^{s}$ - ripple frequency stability factor.

Stability factor of pulsation frequency of group of simultaneously operating milking machines is determined by dependence

$$
k_{f}^{s}=\varphi_{i} \cdot \psi_{f},
$$

where $\varphi_{i}$ - proportion of milking machines, operating at high frequency, in total number of milking machines;

$\psi_{f}$ - proportion of actual frequency increment from its nominal value.

\section{Results and Discussion}

The results of the experiment on the effect of the frequency of pulsations of the group of simultaneously operating milking machines and the load of the vacuum line on the estimated air flow rates are processed by mathematical statistics methods and presented in Table 2 .

The mathematical expectation of the sum $Q_{\Sigma}$ of air flow rates by the vacuum system $Q_{s}$ and regulator $Q_{r}$ is practically unchanged. It is not possible to say this about the dispersion $D_{\Sigma}$ of the sum of the air flow rates $Q_{s}$ by the vacuum system and the air flow rates $Q_{r}$ by the vacuum regulator. With increase in load of the vacuum system the functional dependence on the frequency of pulsations is shown, and the sensitivity is from $0.24 \cdot 10^{-6} \mathrm{~m}^{6} \cdot \mathrm{s}^{-2}$ (with the minimum frequency of pulsations) up to $0.12 \cdot 10^{-6} \mathrm{~m}^{6} \cdot \mathrm{s}^{-2}$. 
Values of estimated flow rates depending on frequency of milking apparatus pulsations and vacuum line load

Table 2

\begin{tabular}{|c|c|c|c|c|c|c|c|}
\hline $\boldsymbol{Q}_{s}, \mathbf{m}^{3} \cdot \mathbf{s}^{-1}$ & $\boldsymbol{D}_{\boldsymbol{s}}, \mathbf{m}^{\mathbf{6}} \cdot \mathbf{s}^{-2}$ & $\boldsymbol{Q}_{r}, \mathbf{m}^{\mathbf{3}} \cdot \mathbf{s}^{-1}$ & $\boldsymbol{D}_{\boldsymbol{r}}, \mathbf{m}^{\mathbf{6}} \cdot \mathbf{s}^{-2}$ & $\boldsymbol{Q}_{\xi}, \mathbf{m}^{3} \cdot \mathbf{s}^{-1}$ & $\boldsymbol{D}_{\xi}, \mathbf{m}^{\mathbf{6}} \cdot \mathbf{s}^{-2}$ & $\boldsymbol{Q}_{\Sigma}, \mathbf{m}^{3} \cdot \mathbf{s}^{-1}$ & $\boldsymbol{D}_{\Sigma}, \mathbf{m}^{\mathbf{6}} \cdot \mathbf{s}^{-2}$ \\
\hline $1.94 \cdot 10^{-3}$ & $3.52 \cdot 10^{-6}$ & $15.64 \cdot 10^{-3}$ & $1.35 \cdot 10^{-6}$ & $13.72 \cdot 10^{-3}$ & $9.21 \cdot 10^{-6}$ & $17.58 \cdot 10^{-3}$ & $0.53 \cdot 10^{-6}$ \\
\hline $3.64 \cdot 10^{-3}$ & $0.53 \cdot 10^{-6}$ & $15.72 \cdot 10^{-3}$ & $0.56 \cdot 10^{-6}$ & $12.08 \cdot 10^{-3}$ & $1.31 \cdot 10^{-6}$ & $19.19 \cdot 10^{-3}$ & $0.60 \cdot 10^{-6}$ \\
\hline $4.58 \cdot 10^{-3}$ & $0.34 \cdot 10^{-6}$ & $14.69 \cdot 10^{-3}$ & $0.42 \cdot 10^{-6}$ & $10.17 \cdot 10^{-3}$ & $1.31 \cdot 10^{-6}$ & $19.36 \cdot 10^{-3}$ & $0.10 \cdot 10^{-6}$ \\
\hline $3.22 \cdot 10^{-3}$ & $0.39 \cdot 10^{-6}$ & $16.28 \cdot 10^{-3}$ & $0.12 \cdot 10^{-6}$ & $13.08 \cdot 10^{-3}$ & $0.94 \cdot 10^{-3}$ & $19.5 \cdot 10^{-3}$ & $0.086 \cdot 10^{-6}$ \\
\hline $4.11 \cdot 10^{-3}$ & $0.28 \cdot 10^{-6}$ & $15.47 \cdot 10^{-3}$ & $0.19 \cdot 10^{-6}$ & $11.36 \cdot 10^{-3}$ & $0.61 \cdot 10^{-6}$ & $19.58 \cdot 10^{-3}$ & $0.33 \cdot 10^{-6}$ \\
\hline $5.25 \cdot 10^{-3}$ & $0.17 \cdot 10^{-6}$ & $14.78 \cdot 10^{-3}$ & $0.19 \cdot 10^{-6}$ & $9.53 \cdot 10^{-3}$ & $0.45 \cdot 10^{-6}$ & $20.03 \cdot 10^{-3}$ & $0.26 \cdot 10^{-6}$ \\
\hline $3.56 \cdot 10^{-3}$ & $1.11 \cdot 10^{-6}$ & $15.25 \cdot 10^{-3}$ & $0.66 \cdot 10^{-6}$ & $11.69 \cdot 10^{-3}$ & $3.41 \cdot 10^{-6}$ & $18.81 \cdot 10^{-3}$ & $0.12 \cdot 10^{-6}$ \\
\hline $5.03 \cdot 10^{-3}$ & $0.14 \cdot 10^{-6}$ & $14.39 \cdot 10^{-3}$ & $0.10 \cdot 10^{-6}$ & $9.36 \cdot 10^{-3}$ & $0.29 \cdot 10^{-6}$ & $19.42 \cdot 10^{-3}$ & $0.17 \cdot 10^{-6}$ \\
\hline $6.56 \cdot 10^{-3}$ & $1.00 \cdot 10^{-6}$ & $13.42 \cdot 10^{-3}$ & $0.07 \cdot 10^{-6}$ & $6.89 \cdot 10^{-3}$ & $1.54 \cdot 10^{-6}$ & $19.72 \cdot 10^{-3}$ & $0.61 \cdot 10^{-6}$ \\
\hline $5.00 \cdot 10^{-3}$ & $0.78 \cdot 10^{-6}$ & $15.36 \cdot 10^{-3}$ & $0.56 \cdot 10^{-6}$ & $9.81 \cdot 10^{-3}$ & $4.14 \cdot 10^{-6}$ & $19.81 \cdot 10^{-3}$ & $0.12 \cdot 10^{-6}$ \\
\hline $5.69 \cdot 10^{-3}$ & $0.53 \cdot 10^{-6}$ & $14.14 \cdot 10^{-3}$ & $0.19 \cdot 10^{-6}$ & $8.44 \cdot 10^{-3}$ & $1.22 \cdot 10^{-6}$ & $19.83 \cdot 10^{-3}$ & $0.24 \cdot 10^{-6}$ \\
\hline $6.33 \cdot 10^{-3}$ & $0.72 \cdot 10^{-3}$ & $13.28 \cdot 10^{-3}$ & $0.18 \cdot 10^{-6}$ & $6.94 \cdot 10^{-3}$ & $1.14 \cdot 10^{-6}$ & $19.58 \cdot 10^{-3}$ & $0.45 \cdot 10^{-6}$ \\
\hline
\end{tabular}

Here, $Q_{s}, Q_{r}, Q_{\xi}, Q_{\Sigma}$ - mathematical expectation of flow rates of the vacuum system, the regulator, differences and the sums between them respectively, $\mathrm{m}^{3} \cdot \mathrm{s}^{-1} ; D_{s}, D_{r}, D_{\xi}, D_{\Sigma}$ - dispersions of flow rates of the vacuum system, the vacuum regulator, differences and the sums between them, respectively, $\mathrm{m}^{6} \cdot \mathrm{s}^{-2}$.

Sensitivity of mathematical expectation of values of the air flow rates $Q_{s}$ of the vacuum system is 20-30 \% more (approximately in 1.3-1.5 times), than sensitivity of mathematical expectation of the air flow rates $Q_{r}$ of the vacuum regulator, fluctuate ranging from $0.54 \cdot 10^{-3}$ up to $0.75 \cdot 10^{-3} \mathrm{~m}^{3} \cdot \mathrm{s}^{-1}$ $\left(0.39 \cdot 10^{-3}-0.53 \cdot 10^{-3} \mathrm{~m}^{3} \cdot \mathrm{s}^{-1}-\right.$ for the air flow rates of the vacuum regulator). Dispersion $D_{s}$ of the air flow rates $Q_{s}$ of the vacuum system $70 \%$ more (approximately by 3,4 times) sensitivity of dispersion $D_{r}$ of the air flow rates $Q_{r}$ of the vacuum regulator, but fluctuations are more considerable - from $0.054 \cdot 10^{-6} \mathrm{~m}^{6} \cdot \mathrm{s}^{-2}$ to $0.80 \cdot 10^{-6} \mathrm{~m}^{6} \cdot \mathrm{s}^{-2}\left(0.015 \cdot 10^{-6}-0.23 \cdot 10^{-6} \mathrm{~m}^{6} \cdot \mathrm{s}^{-2}-\right.$ for dispersion $D_{r}$ of air flow rates of the vacuum regulator).

The coefficient of sensitivity of mathematical expectation $Q_{\xi}$ of a difference between the air flow rates $\left(0.89 \cdot 10^{-3}-1.19 \cdot 10^{-3} \mathrm{~m}^{3} \cdot \mathrm{s}^{-1}\right)$ is 2-6 times higher than sensitivity of mathematical expectation $Q_{\Sigma}$ of the sum of air flow rates; in 1.5-1.8 times higher than sensitivity of mathematical expectation of air flow rates $Q_{s}$ by the vacuum system; in 1.7-2.7 times higher than sensitivity of mathematical expectation $Q_{r}$ of air flow rates of the vacuum regulator.

The coefficient of sensitivity of the dispersion $D_{\xi}$ of difference between the flow rates $Q_{\xi}$ varies considerably. The coefficient of sensitivity of the dispersion $D_{\xi}$ of difference between the flow rates $Q_{\xi}$ exceeds the values of the coefficient of sensitivity of dispersion $D_{\Sigma}$ of the sum of flow rates $Q_{\Sigma}$ by 2-6 times. The coefficient of sensitivity of the dispersion $D_{\xi}$ of difference between the flow rates $Q_{\xi}$ exceeds the values of the coefficient of sensitivity of dispersion $D_{s}$ of flow rates $Q_{s}$ of the vacuum system by 2 times. The coefficient of sensitivity of the dispersion $D_{\xi}$ of the difference between the flow rates $Q_{\xi}$ exceeds the values of the coefficient of sensitivity of dispersion $D_{r}$ of flow rates $Q_{r}$ of the vacuum regulator more than 5.5 times (Some results are shown in the figure).

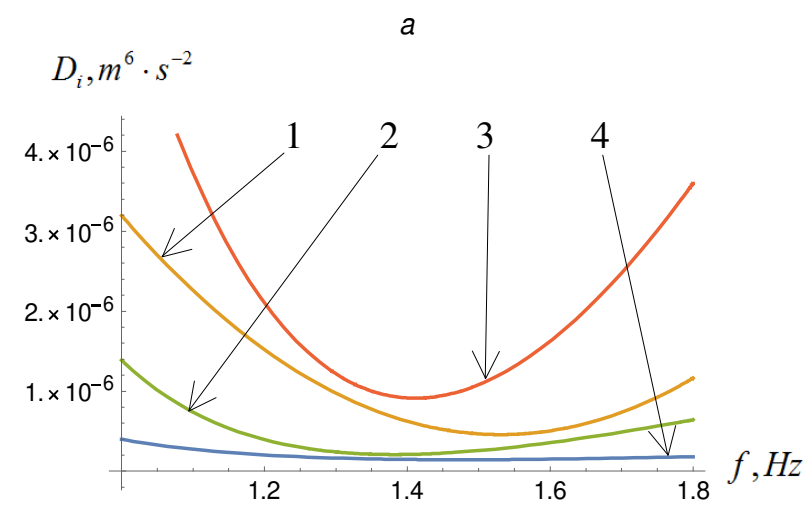

$$
D_{i}, m^{6} \cdot s^{-2}
$$

b

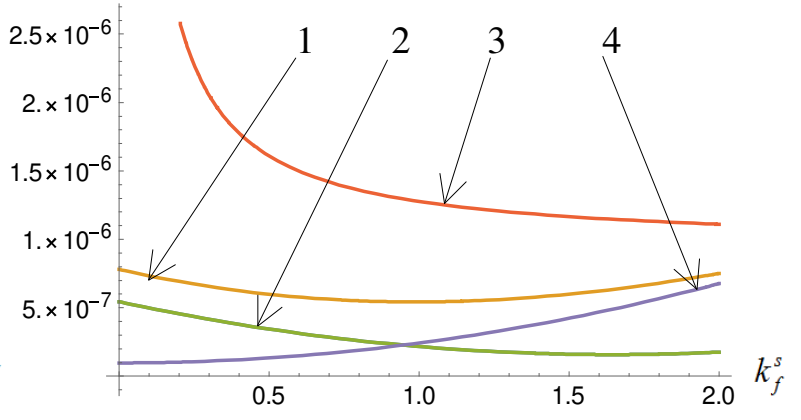




\section{Fig. 1. Dependence of dispersions of controlled parameters on frequency of pulsations $f$ (a) and on coefficient $k_{f}^{s}$ of stability of frequency of pulsations of group of simultaneously operating milking apparatus (b): $1-D_{s} ; 2-D_{r} ; 3-D_{\xi} ; 4-D_{\Sigma}$}

The mathematical expectation of the sum of flow rates $Q_{\Sigma}$ does not depend on the frequency of pulsations and on the load on the vacuum line. We cannot say that about dispersion $D_{\Sigma}$. The minimum value of the coefficient of sensitivity of the dispersion $D_{\Sigma}$ of the sum of flow rates $Q_{\Sigma}$ is $0.52 \cdot 10^{-6} \mathrm{~m}^{6} \cdot \mathrm{s}^{-2} \cdot \mathrm{Hz}^{-1}$, high $-0.79 \cdot 10^{-6} \mathrm{~m}^{6} \cdot \mathrm{s}^{-2} \cdot \mathrm{Hz}^{-1}$. More sensitive mathematical expectation of air flow rates $Q_{s}$ by the vacuum system and air flow rates $Q_{r}$ by the vacuum regulator $\left(1.75 \cdot 10^{-3}\right.$ $3.42 \cdot 10^{-3} \mathrm{~m}^{3} \cdot \mathrm{s}^{-1} \cdot \mathrm{Hz}^{-1}$ and $1.61 \cdot 10^{-3}-2,19 \cdot 10^{-3} \mathrm{~m}^{3} \cdot \mathrm{s}^{-1} \cdot \mathrm{Hz}^{-1}$, respectively), as well as their dispersions $D_{s}, D_{r}$ $\left(0.49 \cdot 10^{-6}-9.49 \cdot 10^{-6} \cdot 10^{-6} \mathrm{~m}^{6} \cdot \mathrm{s}^{-2} \cdot \mathrm{Hz}^{-1}\right.$ and $0.43 \cdot 10^{-6}-3.70 \cdot 10^{-6} \cdot 10^{-6} \mathrm{~m}^{6} \cdot \mathrm{s}^{-2} \cdot \mathrm{Hz}^{-1}$, respectively).

With an increase in the load on the vacuum line to ten milking machines, the variability of the mathematical expectation of the difference in the flow rates $Q_{\xi}$ from the pulsation frequency increases. The value of the sensitivity coefficient reaches $4.11 \cdot 10^{-3} \mathrm{~m}^{3} \cdot \mathrm{s}^{-1} \cdot \mathrm{Hz}^{-1}$, which is higher than the corresponding sensitivity coefficient of the sum of the flow rates $Q_{\Sigma}$ by 5.3 times, the air flow rates $Q_{s}$ by the vacuum system - by 1.7 times and the air flow rates $Q_{r}$ by the vacuum regulator - by 2.7 times.

The large scatter of values is explained by the peculiarity of the work of a group of milking apparatus on one vacuum line - the synchronism of some and the asynchrony of others. An analysis of the dependences of the studied parameters on the stability of the pulsation frequency $k_{f}^{s}$ revealed an insignificant sensitivity of the mathematical expectation of the total flow $Q_{\Sigma}\left(0.14 \cdot 10^{-3} \mathrm{~m}^{3} \cdot \mathrm{s}^{-1}\right)$, a slightly greater sensitivity of the mathematical expectation of the air flow rates $Q_{s}$ by the vacuum system $\left(0.69 \cdot 10^{-3} \mathrm{~m}^{3} \cdot \mathrm{s}^{-1}\right)$ and the maximum sensitivity of the air flow rates $Q_{r}$ by the vacuum regulator $\left(1.53 \cdot 10^{-3} \mathrm{~m}^{3} \cdot \mathrm{s}^{-1}\right)$ and the difference between the flow rates $Q_{\xi}\left(1.42 \cdot 10^{-3} \mathrm{~m}^{3} \cdot \mathrm{s}^{-1}\right)$. The sensitivity coefficient of dispersion $D_{\xi}$ of the difference between the flow rates $Q_{\xi}$ significantly exceeds the coefficient values for the remaining parameters $\left(0.59 \cdot 10^{-6} \mathrm{~m}^{6} \cdot \mathrm{s}^{-2}\right.$ versus $\left.0.25 \cdot 10^{-6}-0.36 \cdot 10^{-6} \mathrm{~m}^{6} \cdot \mathrm{s}^{-2}\right)$ (Figure).

\section{Conclusions}

Analysis of the dynamics of changes in the air flow rate by the vacuum system and the vacuum regulator allows us to predict the operation of the milking unit in a malfunctioning state and take timely measures to exclude such operating modes. Greater sensitivity is achieved by using an estimated function as a controlled parameter in the form of a composition of the air flow rate of the vacuum system and the air flow rate of the vacuum regulator. The coefficient of sensitivity of mathematical expectation of a difference between the air flow rates is 2-6 times higher than sensitivity of mathematical expectation of the sum of the air flow rates; in 1.5-1.8 times higher than sensitivity of mathematical expectation of the air flow rates by the vacuum system; in 1.7-2.7 times higher than sensitivity of mathematical expectation of the air flow rates of the vacuum regulator. The coefficient of sensitivity of the dispersion $D_{\xi}$ of difference between the flow rates $Q_{\xi}$ exceeds the values of the coefficient of sensitivity of dispersion $D_{\Sigma}$ of the sum of the flow rates $Q_{\Sigma}$ by 2-6 times. The coefficient of sensitivity of the dispersion $D_{\xi}$ of difference between the flow rates $Q_{\xi}$ exceeds the values of the coefficient of sensitivity of dispersion $D_{s}$ of the flow rates $Q_{s}$ of the vacuum system by 2 times. The coefficient of sensitivity of the dispersion $D_{\xi}$ of the difference between the flow rates $Q_{\xi}$ exceeds the values of the coefficient of sensitivity of dispersion $D_{r}$ of the flow rates $Q_{r}$ of the vacuum regulator more than 5.5 times.

\section{References}

[1] Цой Ю.А., Баишева Р.А. Технологические аспекты создания “умной” фермы (Technological aspects of smart dairy farm development). Аграрная наука Евро-Северо-Востока (Agricultural Science Euro-North-East). - 2019. - T. 20, No.2. - pp. 192-199. (In Russian).

[2] Цой Ю.А., Баишева Р.А., Кормановский Л.П. Повышение надежности функционирования эргатических систем управления молочной фермой (Improvement of Functioning Reliability of Dairy Farm Ergotic Control Systems). Электротехнологии и электрооборудование в АПК (Electrical technologies and electrical equipment in agriculture). - 2018. - No.4(33). - pp. 90-94. [online][11.02.2020] Available at: http://vestnik.viesh.ru/jour-nal/vypusk-4-33-2018/. (In Russian) 
[3] Pedersen S.M., Lind K.M. (eds.), (2017). Precision Agriculture: Technology and Economic Perspectives, Progress in Precision Agriculture. DOI: 10.1007/978-3-319-68715-5_2.

[4] Schönfeld V., Max \& Heil, Reinhard \& Bittner, Laura. (2018). Big Data on a Farm - Smart Farming. DOI: 10.1007/978-3-319-62461-7_12.

[5] Nayyar A., Puri V. Smart farming: IoT based smart sensors agriculture stick for live temperature and moisture monitoring using Arduino, cloud computing \& solar technology., 2016, pp.673-680. DOI: 10.1201/9781315364094-121.

[6] Britt J.H., Cushman R.A., Dechow C.D., Dobson H., Humblot P., Hutjens M.F. et al. Invited review: Learning from the future - A vision for dairy farms and cows in 2067. Journal of Dairy Science. 101(5), 2018, pp. 3722 - 3741. DOI: 10.3168/jds.2017-14025.

[7] Ушаков Ю.А. Инженерные методы обеспечения качества молока (Engineering methods for ensuring milk quality). Дис. д.т.н., Оренбург, 2011. -376 p. (In Russian).

[8] Rasmussen M.D., Reinemann D.J., Mein G.A. Measuring vacuum in milking machines. From Bulletin № 381 of the International Dairy Federation 2003.

[9] Ушаков Ю.А. Повышение эффективности вакуумной линии доильной установки (Improving the efficiency of the vacuum line milking unit)/Ю.А. Ушаков // Техника в сельском хозяйстве (Agricultural machinery). - М., 1997. - No. 4. - pp. 19-20. (In Russian).

[10] Карташов Л.П. О контролируемых параметрах вакуумной системы доильной установки (On the controlled parameters of the vacuum system of the milking unit)/Л.П. Карташов, Ю.А. Ушаков // Вестник Оренбургского государственного университета (Bulletin of Orenburg State University). - 2011. - No. 8. - pp. 220-223. (In Russian).

[11] Ушаков Ю.А. Влияние некоторых параметров вакуумной системы на оценочные показатели расходов, их алгебраических комбинаций (The influence of some parameters of the vacuum system on the estimated flow rates, their algebraic combinations)/Ю.А. Ушаков, Н.Г. Данилова, И.И. Герасименко // Международный научно-исследовательский журнал «Успехи современной науки и образования» (International Research Journal „Advances in Modern Science and Education”)/Белгород: Издательский центр «Эпицентр», 2017. - No.3. Том 4. - pp. 127-131.

[12] Ushakov Y.A. Method for diagnosing the tightness of milk pipes milking installations)/Y.A. Ushakov, V.A. Shakhov, E.M.Asmankin, N.G.Danilova,N.A. Pugachtva // VI SCIENTIFIC CONGRESS. "AGRICULTURAL MACHINERY". 25-28.06.2018. PROCEEDINGS. Volume 1: Agricultural machines. Research and testing. New machine designs. YEAR II. Burgas, Bulgaria. 2018, pp. 63-65.

[13]ГОСТ 28545-90 (ИСО 5707-83). Установки доильные. Конструкция и техническая характеристика (Milking machine installations. Construction and performance). Издательство стандартов. - Москва (Moscow: publishing house of standards, 1998). - 1998. - 17p. (In Russian). 